\title{
New Post-COVID-19 Biosafety Protocols in Pediatric Dentistry
}

\author{
Lívia Mund de Amorim ${ }^{1}$, Tamires Timm Maske ${ }^{2} \mathbb{1}$, Simone Helena Ferreira ${ }^{3}(\mathbb{D}$, Rubem Beraldo dos

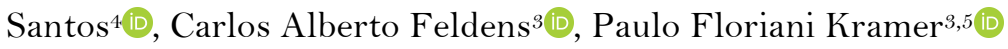

\begin{abstract}
${ }^{1}$ Postgraduate Program in Dentistry, School of Dentistry, Lutheran University of Brazil, Canoas, RS, Brazil. ${ }^{2}$ Postgraduate Program in Dentistry, School of Dentistry, Federal University of Pelotas, Pelotas, RS, Brazil. ${ }^{3}$ Department of Pediatric Dentistry, School of Dentistry, Lutheran University of Brazil, Canoas, RS, Brazil. ${ }^{4}$ Department of Clinical Dentistry, School of Dentistry, Lutheran University of Brazil, Canoas, RS, Brazil.

${ }^{5}$ Department of Pediatric Dentistry, School of Dentistry, Pontifical Catholic University of Rio Grande do Sul, Porto Alegre, RS, Brazil.
\end{abstract}

Author to whom correspondence should be addressed: Lívia Mund de Amorim, Postgraduate Program in Dentistry, School of Dentistry, Lutheran University of Brazil, Canoas, RS, Brazil. Phone: +55 5134774000. E-mail: liviamamorim@hotmail.com.

Academic Editor: Alessandro Leite Cavalcanti

Received: 02 June 2020 / Accepted: 13 June 2020 / Published: 22 June 2020 How to cite this article: Amorim LM, Maske TT, Ferreira SH, Santos RB, Feldens CA, Kramer PF. New post-COVID-19
biosafety protocols in pediatric dentistry. Pesqui Bras Odontopediatria Clín Integr. 2020; 20(supp1):e0117.
https://doi.org/10.1590/pboci.2020.117

\begin{abstract}
The most recent Severe Acute Respiratory Syndrome - COVID-19 - caused by coronavirus infection (SARS-CoV-2) has high-virulence transmission and direct human contagiousness by proximity. Thus, the considerable occupational risk in pediatric dentistry is evident, given the nature and form of procedures performed in an outpatient setting. Thus, the aim of this paper was to identify and contextualize technical and scientific information available to date aimed at preventing and minimizing risks for patients, caregivers and professionals. The results indicate that protective measures are being developed considering procedures according to risks and benefits, and five points stand out: 1. Regulation of resumption of elective procedures, screening and scheduling patients; 2. Restructuring clinical environment and infection control; 3. Improvement of personal protective equipment and biosafety recommendations; 4. Maximization of the use of non-invasive techniques, use of high-powered dental suction, and absolute isolation of the operative field; and 5. Minimization of the use of air-water syringe, dental spittoon and high-speed handpiece. The measures to be taken require reflection for the restart of a "new clinical practice", especially aiming at behavioral and structural changes regarding operational biosafety.
\end{abstract}

Keywords: Coronavirus; Pediatric Dentistry; Dental Care; Clinical Protocols. 


\section{Introduction}

COVID-19 is a viral infection caused by the novel coronavirus (SARS-CoV-2), identified in December 2019 in the city of Wuhan in China. Rapidly evolving and spreading, it was characterized in January 2020 as a public health emergency by the World Health Organization (WHO) [1]. In view of the growing number of cases and localities involved, in March 2020, it was declared a global pandemic outbreak affecting 170 regions and countries, with more than 400 thousand confirmed cases [2].

The transmission model of the novel coronavirus and its high virulence involve direct and indirect human contagiousness by proximity, potentially spreading through saliva and respiratory fluids [3,4]. During the pandemic, most health teams, especially in the medical field, acquired the disease during the care of infected individuals. In dentistry, there is a considerable occupational risk given the nature of procedures performed on an outpatient setting, making patient care a potential challenge in coping with this disease $[1,5]$.

Dental practice involves procedures with great physical proximity between professional and patient, associated with the generation of aerosols that culminate in water, saliva and blood droplets and pathogenic microorganisms. Recent studies have demonstrated the role of the oral mucosa in COVID-19 infection, in addition to expressing the ACE2 receptor in salivary glands in the asymptomatic process in infected saliva, thus being one of the main sources of viruses [6]. In addition, contaminated surfaces in the workplace perpetuate the virus's survival for up to five days [4,7,8]. Despite the potential transmission and contamination, there are still no studies assessing the risk of SARS-CoV-2 transmission during dental care or determining the description of the risk for the dental team regarding exposure and risk of cross-contamination $[3,9]$.

In view of the current scenario, new adversities of occupational risk emerge and are opposed to the decision-making process by pediatric dentists. Considering that pediatric dentistry has particularities related to the behavioral approach strategies and active participation of parents and caregivers, the institution of new guidelines is necessary and should be aimed at preventing and minimizing potential risk for both professionals and patients and caregivers during and after the coronavirus pandemic [10].

This study aimed to contextualize and synthesize technical and scientific information available so far to minimize contamination risks in post-COVID-19 pediatric dentistry.

\section{Scientific Evidence and Decision Making}

Typical clinical symptoms manifested in patients affected by COVID-19 are dry cough, fever, myalgia or fatigue, difficulty breathing and, in some cases, diarrhea [11,12]. Partial or total loss of smell (hyposmia / anosmia) and taste change (dysgeusia / hypogeusia / ageusia) also stand out. These prodromal signs can progress to severe pneumonia with multiple organ failure [13]. However, mortality rates are predominantly observed in elderly patients and in the presence of pre-existing comorbidities, such as cardiovascular diseases, hypertension, diabetes, chronic respiratory diseases, and cancer [14].

Most children have a benign course of the disease, with mild respiratory symptoms and low frequency of deaths, making it difficult to estimate the true incidence of the virus in these individuals [15]. Belowexpected rates in children affected by COVID-19 may be related to decreased exposure and infection by the virus and by immunity to other coronaviruses, consequently decreasing the likelihood of developing the disease, even when infected $[2,15]$.

Drugs such as chloroquine and its hydroxychloroquine analog, used in the treatment of autoimmune diseases, have antiviral properties and immunomodulatory effects. However, the absence of conclusive clinical 
trials rules out, at least at this moment, their use in patients with COVID-19 [16]. Other drugs, such as antiretrovirals and antimicrobials, experimentally administered to adult hospitalized patients with severe infection, have also been shown to be ineffective or inconclusive [14]. More recent studies have shown that the development of a vaccine will depend on research aimed at the genetic sequencing of SARS-CoV-2 [17].

Protection guidelines for dental care during the COVID-19 pandemic are being developed based on grouping patients according to condition and need, and considering procedures according to risks and benefits. As new data emerge, intermediate guideline algorithms based on the latest recommendations from health agencies and scientific literature are provided [18].

Data indicate that the demand for dental emergencies had a $38 \%$ reduction, even though it is characterized as essential care during the pandemic. Regulatory and advisory agencies also mention the lack of clarity regarding the possible impact that the pandemic will have on dental services. However, it is speculated that dental demand may increase exponentially in the post-COVID-19 period [19].

Considering that the development of some vaccine method is in progress, but estimating that it will not be available for at least one year, norms for dental procedures must be improved and remain in force in order to contain the virus and prevent its recurrence [2]. Therefore, in view of the specificities inherent to the activity, pediatric dentistry has discussed infection control strategies and flowcharts and safety recommendations aimed at resuming clinical care.

\section{Clinical Protocols}

Clinical protocols have been developed by institutional agencies linked to health and dentistry, prioritizing the safety and well-being of professionals and adult and child patients [20,21]. Table 1 shows national and international documents [22-30] and an address for consulting dental care guidelines during COVID-19 in force today.

A summary of the clinical protocols in force today against the pandemic will be presented, with emphasis on guidelines and strategies related to biosafety and treatment plan in pediatric dentistry. When possible, elective treatments should be avoided, prioritizing urgent procedures such as pain, edema, hemorrhage and dentoalveolar trauma. In addition, considering that most patients may be asymptomatic, slightly symptomatic or at the incubation period (estimated between 1 and 14 days), all patients should be treated as if they are contaminated [29,31]. Protocols are didactically divided into four distinct moments of dental care: patient screening, preoperative, operative, and postoperative periods.

\section{Patient Screening}

The scheduling of patients will be performed via telephone contact or online guidance, such as using WhatsApp ${ }^{\circledR}$ or similar, always by appointment. Caregivers must inform in advance if the child has been unwell and feverish in the last 24 hours. If so, the appointment should be rescheduled. Patients are asked to arrive on time, avoid more than one companion and use face mask. Attendances will be more spaced so that there is no crowding in the waiting room and also more time for cleaning and disinfecting physical spaces.

Brief medical history is important as some chronic diseases such as asthma, diabetes and immunodeficiencies are responsible for increasing the chance of severe COVID-19, even in children [32]. If the child tests positive for COVID-19 and needs attendance, it should be scheduled at the end of the day due to the high transmissibility and permanence of the virus in the environment [33]. 
Table 1. Biosafety protocols against COVID-19.

\section{Institutional Agency}

Brazilian Federal Council of Dentistry (CFO) [22]

Regional Council of Dentistry of the State of São Paulo (CRO-SP) [23]

Brazilian Health Regulatory Agency (ANVISA) [24]

World Health Organization (WHO) [25]

World Dental Federation (FDI) [26]

American Dental Association (ADA) [27]

Latin American Association of Pediatric Dentistry (ALOP) [28]

American Academy of Pediatric Dentistry (AAPD) [29]

International Association of Paediatric Dentistry (IAPD) [30]

\section{Document Reference}

Manual de Boas Práticas em Biossegurança para Ambientes Odontológicos

Orientação de Biossegurança. Adequações Técnicas em Tempos de COVID-19

Orientações para Serviços de Saúde: Medidas de Prevencạ̃o e Controle que Devem ser Adotadas Durante a Assistência aos Casos Suspeitos ou Confirmados de Infecção pelo Novo Coronavírus (SARS-CoV-2)

Infection Prevention and Control During Health Care When Novel Coronavirus (Ncov) Infection is Suspected COVID-19 Outbreak: Guidance for Oral Health Professionals

Return to Work Interim: Guidance Toolkit

Tratamiento de la Enfermedad de Caries en Época de COVID-19: Protocolos Clínicos para el Control de Aerosoles Re-emergence Pediatric Dentistry Practice Checklist International Pulmonologist's Consensus on COVID-19

\section{$\begin{array}{ll}\text { Table 2. Attention in the operative care of pediatric patients. } & \text { Adaptations of Techniques and Equipments }\end{array}$}

All children - The air-water syringe must be used with care; and replace washing with a syringe with saline.

- Preference for drying with cotton and gauze.

- Minimize the use of the dental spittoon, with constant saliva suction, preferably with dental vacuum pump.

- Attention and care in the handling medications and dental materials to avoid cross-infection.

Children who require protective stabilization

- The companion must assist in patient restraint with mask and goggles. The assistance aims not to overload the dental staff, since contact with body fluids such as sweat is inherent to this type of approach.

Immunologically compromised children

- They should be scheduled as the first appointment of the day, minimizing the risk of exposure to the environment, with increased attention to infection control and air turnover, given their increased susceptibility when infected by SARS-CoV-2, in addition to having medical contact for clarifications.

Children who require urgent treatments

- Such children should have their procedures maximized, preferably aimed at the adequacy of the oral environment, and avoiding recurring visits to the dental office.

Children with caries lesions with or without restorative needs

- Consider the risk of dental caries, directing strategies for the treatment of active caries lesions in enamel and dentin;

- Use fluoride varnishes, silver diamine fluoride, pit and fissure sealants, temporary and atraumatic restorations, in addition to constant reinforcement of the diet and use of fluoride toothpaste.

- Restorative treatment must be performed by quadrants under rubber dam isolation, reducing the production of saliva, aerosol and particles contaminated by blood.

- If possible, choose non-aerosol-generating restorative procedures. Use high-speed handpiece without water spray; and give preference to manual instruments and low rotation. 
The availability of online applications and resources facilitates prior contact with parents and guardians as a way of screening patients. Thus, it is possible to more accurately identify the complaint and reason for dental care, including sharing photos and images, facilitating the elaboration of the treatment plan. Extra-oral radiography is preferred as a diagnostic aid, considering that intra-oral radiography induces salivation and favors cross-contamination [27].

Caregivers should also be asked to inform the pediatric patients in advance, according to their degree of understanding, that the dental office environment will be different from the usual, without toys for distraction in the waiting room, in addition to the characterization and vestment of the professional team in order to minimize possible patient's aversion and awkwardness. A professional video record regarding the use of the Personal Protective Equipment (PPE) could be provided to the caregivers aiming the child's guidance before arriving at the dental office. It was also requested that only one caregiver should accompany the child and that the child preferably has no medical history of comorbidities. The presence of elderly people should be avoided in view of their greater potential risk for COVID-19.

\section{Preoperative Period}

Care and measures to be taken in this topic are critical to prevent SARS-CoV-2 transmission to children, as well as the transmission from infected children to professionals and other patients [4,34]. Visual alerts (signs and posters) at the office's entrance and in strategic locations (waiting areas and elevators) are alternative resources to reinforce biosafety instructions.

The waiting room should have spacing between chairs and common handling objects such as magazines and toys should be removed in order to avoid surfaces exposed to contamination. There will also be availability and easy access to hand sanitizer in different office settings [22,23,27].

Environments should be well ventilated, preferably with open windows to renew the circulating air in order to reduce contamination by droplets suspended in the environment and deposited on surfaces for long periods [7,24]. It is suggested to follow strict protocols of periodic cleaning of the air conditioning system and the installation of high-performance air filters.

Upon arrival at the office, there will be no hand greetings, kisses or hugs and, even at the entrance, the body temperature of patient and companion should be checked using a thermometer, preferably infrared. In case of fever, the child should be referred for medical assistance. Personal protective equipment such as a shoe protector and cap for the child and companion will be provided. When properly dressed, the patient will be instructed to wash hands before entering the clinical room. In addition, the use of face mask, exclusive and personal, is recommended until the time of service.

The use of $1 \%$ hydrogen peroxide through mouthrinse has been recommended due to its oxidative potential and consequent reduction of COVID-19 viral load. The use of $0.12 \%$ chlorhexidine digluconate, in turn, still lacks more robust scientific evidence. In children, the use of manipulated $1 \%$ hydrogen peroxide with the addition of flavorings has been recommended by frictioning sterile gauze soaked in the solution. The use of mouthwashes is exclusively for pre-procedure, and continuous use by the patient is not recommended $[23,24,35,36]$.

\section{Operative Period}

Standard precautions should be adopted, such as minimizing objects on surfaces, aim to reduce crosscontamination, remaining only instruments and individualized consumption material available for the patient 
to be attended [37]. The professional must remove earrings, rings, necklaces, bracelets and watches. Men should avoid wear beard and women over-makeup for better sealing and effectiveness of the face mask (respirators). The pediatric patient's approach should be friendly, exposing the situation with normality and being positive and motivating. It is suggested to avoid prolonging conversations focused on difficulties and adversities, especially related to the pandemic period [29].

Regarding PPE, the dentist must wear type N95 or at least PFF-2 respirator (without valve); waterproof and disposable gown; cap; protective goggles; disposable gloves and face mask [24]. The correct sequence of PPE dressing involves: 1st - Putting on the mask; 2nd - Putting on protective goggles; 3rd Putting on the cap; 4th - Putting on the face shield; 5th - Putting on the disposable gown; and 6th - Putting on protective gloves. The removal of PPE must follow the reverse order [36]. Table 2 describes the adaptations of pediatric care, including patient management, as well as techniques and equipment to reduce occupational risks related to COVID-19.

\section{Postoperative Period}

The postoperative period involves the patient's care and supervision as well as the after-attendance environment procedures. The availability of the professional in the post-care period is part of treatment, especially in situations that require pain management that generate anxiety. Patient recalls, in turn, must take into account the risks and benefits of a dental appointment during the COVID-19 pandemic.

The medication regimen for pain management in children remains the usual prescription manner using analgesics (oral suspension or tablets), respecting the maximum dose according to the child's weight. In the presence of systemic symptoms (fever, loss of appetite, prostration) followed by edema and acute infectious signs, the usual prescription of antibiotics (oral suspension or tablets) is maintained under supervision if dental procedure has been performed [38].

Preventive measures must be reinforced for the patient. Changes in the child's routine may include increased consumption of sugary foods. To this end, the access to these foods should be limited, also reinforcing hygiene habits with continued supervision and regular use of fluoride toothpaste.

After attendance, appropriate procedures for cleaning and disinfecting the environment and surfaces must be carried out. This should take place after a period of 1 to 2 hours for aerosol particles to settle on surfaces [36]. Disinfection of units should only be carried out after their previous cleaning, and in the following order: from the least contaminated to the most contaminated area; from top to bottom, and from inside out. Cleaning surfaces with neutral detergent is recommended, followed by disinfection with disinfectant solutions, such as $70 \%$ alcohol and $1 \%$ sodium hypochlorite [3,24].

Waste management, in turn, must be performed in a safe and environmentally correct manner to avoid environmental impact. The residence time of coronavirus in residues can be up to 5 hours. Residues must be packed in impermeable bags made of material resistant to rupture and leakage, and placed in closed containers until collection by specialized services.

\section{Conclusion}

Measures to be taken during dental care after COVID-19 pandemic require reflection for the resumption of clinical practice, especially regarding behavioral changes aimed at operational biosafety. There is a set of strategic alternatives and specific preventive improvements to be planned and executed before, during and after care based on information that has emerged during the COVID-19 pandemic. The notes of resources 
for the practice of pediatric dentistry presented are a compilation of recommendations from national and international agencies and councils based on scientific evidence. However, it is important to consider that currently, there is no universal protocol for the management of patients with COVID-19. The search for new information must be constant and continuous to deliver to the pediatric patient humanized and effective treatment, with minimization of risks during dental care.

\section{Authors' Contributions}

$\begin{array}{lll}\text { LMA } & \text { (D) } 0000-0002-0211-4138 & \text { Conceptualization and Writing - Original Draft Preparation. } \\ \text { TTM } & \text { (D) } 0000-0002-2708-5337 & \text { Conceptualization and Writing-Original Draft Preparation. } \\ \text { SHF } & \text { (D) } 0000-0002-7052-7014 & \text { Writing - Review and Editing. } \\ \text { RBS } & \text { (D) } 0000-0002-6304-1235 & \text { Writing - Review and Editing. } \\ \text { CAF } & \text { (D) } 0000-0002-9783-9309 & \text { Writing - Review and Editing. } \\ \text { PFK } & \text { (D) } 0000-0002-3378-3545 & \text { Conceptualization and Writing - Original Draft Preparation. } \\ \text { All authors declare that they contributed to critical review of intellectual content and approval of the final version to be } \\ \text { published. }\end{array}$

\section{Financial Support}

Coordenação de Aperfeiçoamento de Pessoal de Nível Superior - Brasil (CAPES) - Private IES Graduate Support Program (Process No. 88887.479638/2020-00).

\section{Conflict of Interest}

The authors declare no conflicts of interest.

\section{References}

[1] Khader Y, Al Nsour M, Al-Batayneh OB, Saadeh R, Bashier H, Alfaqih M, et al. Dentists' awareness, perception, and attitude regarding COVID-19 and infection control: cross-sectional study among Jordanian dentists. JMIR Public Health Surveill 2020; 6(2):e18798. https://doi.org/10.2196/18798

[2] Rasmussen SA, Thompson LA. Coronavirus disease 2019 and children: what pediatric health care clinicians need to know. JAMA Pediatr 2020. https://doi.org/10.1001/jamapediatrics.2020.1224

[3] Centers for Disease Control and Prevention. Guidance for Dental Settings. Available from: https://www.cdc.gov/coronavirus/2019-ncov/hcp/dental-settings.html. [Accessed on May 05, 2020].

[4] Mallineni SK, Innes, NP, Raggio DP, Araujo MP, Robertson MD, Jayaraman J. Coronavirus disease (COVID-19): characteristics in children and considerations for dentists providing their care. Int J Paediatr Dent 2020; 30:245-50. https://doi.org/10.1111/ipd.12653

[5] Zemouri C, de Soet H, Crielaard W, Laheij A. A scoping review on bio-aerosols in healthcare and the dental environment. PLoS One 2017; 12(5):e0178007. https://doi.org/10.1371/journal.pone.0178007

[6] Xu J, Li Y, Gan F, Du Y, Yao Y. Salivary glands: potential reservoirs for COVID-19 asymptomatic infection. J Dent Res 2020; 22034520918518. https://doi.org/10.1177/0022034520918518

[7] Kampf G, Todt D, Pfaender S, Steinmann E. Persistence of coronaviruses on inanimate surfaces and their inactivation with biocidal agents. J Hosp Infect 2020; 104(3):246-51. https://doi.org/10.1016/j.jhin.2020.01.022

[8] Ge ZY, Yang LM, Xia JJ, Fu XH, Zhang YZ. Possible aerosol transmission of COVID-19 and special precautions in dentistry. J Zhejiang Univ Sci B 2020; 21(5): 361-8. https://doi.org/10.1631/jzus.B2010010

[9] Peng X, Xu X, Li Y, Cheng L, Zhou X, Ren B. Transmission routes of 2019-nCoV and controls in dental practice. Int J Oral Sci 2020; 12(1):9. https://doi.org/10.1038/s41368-020-0075-9

[10] Meyer BD, Casamassimo PS, Vann Jr WF. An algorithm for managing emergent dental conditions for children. J Clin Pediatr Dent 2019; 43(3):201-6. https://doi.org/10.17796/1053-4625-43.3.10

[11] Lauer SA, Granz KH, Bi Q, Jones FK, Zheng Q, Meredith HR, et al. The incubation period of coronavirus disease 2019 (COVID-19) from publicly reported confirmed cases: estimation and application. Annals Int Med 2020; 172(9):577-82. https://doi.org/10.7326/M20-0504

[12] Huang C, Wang Y, Li X, Ren L, Zhao J, Hu Y, et al. Clinical features of patients infected with 2019 novel coronavirus in Wuhan, China. 2020. Lancet 395(10223):497-506. https://doi.org/10.1016/So 140-6736(20)30183-5

[13] Giacomelli A, Pezzati L, Conti F, Bernacchia D, Siano M, Oreni L. Self-reported olfactory and taste disorders in SARS-CoV-2 patients: a cross-sectional study. Clin Infect Dis 2020; ciaa330. https://doi.org/10.1093/cid/ciaa330 
[14] Jamal M, Shah M, Almarzooqi SH, Aber H, Khawaja S, El Abed R. Overview of transnational recommendations for COVID-19 transmission control in dental care settings. Oral Dis 2020. https://doi.org/10.1111/odi.13431

[15] Kam KQ, Yung CF, Cui L, Tzer Pin Lin R, Mak TM, Maiwald M, et al. A well infant with coronavirus disease 2019 with high viral load. Clin Infect Dis 2020; ciaa201. https://doi.org/10.1093/cid/ciaa201

[16] Deveaux CA, Rolain JM, Colson P, Raoult D. New insights on the antiviral effects of chloroquine against coronavirus: what to expect for COVID-19? Int J Antimicrob Agents 2020; 55(5):105938. https://doi.org/10.1016/j.ijantimicag.2020.105938

[17] Zhang N, Li C, Hu Y, Li K, Liang J, Wang L, et al. Current development of COVID-19 diagnostics, vaccines and therapeutics. Microbes Infect 2020. https://doi.org/10.1016/j.micinf.2020.05.001

[18] Garritty CM, Norris SL, Moher D. Developing WHO rapid advice guidelines in the setting of a public health emergency. J Clin Epidemio 2017; 82:47-60. https://doi.org/10.1016/j.jclinepi.2016.08.010

[19] Alharbi A, Alharbi S, Alqaidi S. Guidelines for dental care provision during the COVID-19 pandemic. Saudi Dent J 2020; 32(4):181-6. https://doi.org/10.1016/j.sdentj.2020.04.001

[20] American Dental Association. ADA Interim Guidance for Management of Emergency and Urgent Dental Care. Available from: https://www.ada.org/ /media/CPS/Files/COVID/ADA_Int_Guidance_Mgmt_EmergUrg_Dental_COVID19?utm_source=adaorg\&utm_medium=VanityURL\&utm_content=interimguidanceflowcharts\&utm_campaign=covid-19. [Accessed on May 03, 2020].

[21] American Academy of Pediatric Dentistry. COVID-19 Update/Coronavirus Update. Available from: https://www.aapd.org/about/about-aapd/news-room/covid-19/. [Accessed on April 28, 2020].

[22] Brasil. Conselho Federal de Odontologia. Manual de Boas Práticas em Biossegurança para Ambientes Odontológicos. Available from: http://website.cfo.org.br/wp-content/uploads/2020/04/cfo-lança-Manual-de-Boas-Práticas-emBiossegurança-para-Ambientes-Odontologicos.pdf. [Accessed on May 05, 2020]. [In Portuguese].

[23] Brasil. Conselho Regional de Odontologia de São Paulo. Orientações de Segurança. Adequações Técnicas em Tempos de COVID-19. Available from: http://www.crosp.org.br/uploads/arquivo/747df5ff505e7beff33c1a5ff5d6f12a.pdf. [Accessed on May 05, 2020]. [In Portuguese].

[24] Brasil. Agência Nacional de Vigilância Sanitária. Nota Técnica GVIMS/GGTES/ANVISA No 04/2020. Available from: $\quad$ http://portal.anvisa.gov.br/documents/33852/271858/Nota+Técnica+n+042020+GVIMS-GGTESANVISA/ab598660-3de4-4f14-8e6f-b9341c196b28. [Accessed on May 10, 2020]. [In Portuguese].

[25] World Health Organization. Infection prevention and control during health care when novel coronavirus (nCoV) infection is suspected. Available from: https://www.who.int/publications-detail/infection-prevention-and-controlduring-health-care-when-novel-coronavirus-(ncov)-infection-is-suspected-20200125. [Accessed on May 10, 2020].

[26] World Dental Federation. COVID-19 Outbreak: Guidance for Oral Health Professionals. Available from: https://www.fdiworlddental.org/covid-19-outbreak-guidance-for-oral-health-professionals [Accessed on May 10, 2020].

[27] American Dental Association. Return to Work Interim Guidance Toolkit. Available from:https://success.ada.org/ /media/CPS/Files/OpenFiles/ADA_Return_to_Work_Toolkit.pdf . [Accessed on May 10, 2020].

[28] Associación Latinoamericana de Odontopediatria. Tratamiento de la enfermedad de caries en época de COVID-19: protocolos clínicos para el control de aerosoles. Available from: https://www.revistaodontopediatria.org/ediciones/2020/2/art-2/ - art1. [Accessed on May 05, 2020]. [In Spanish]

[29] American Academy of Pediatric Dentistry. Re-emergence pediatric dentistry practice checklist. Available from: https://www.aapd.org/globalassets/media/covid-19/aapd-practicechecklist.pdf. [Accessed on May 05, 2020].

[30] International Association of Paediatric Dentistry. International Pulmonologist's Consensus on COVID-19. Available from: https://www.unah.edu.hn/dmsdocument/9674-consenso-internacional-de-neumologos-sobre-covid-19version-ingles. [Accessed on May 05, 2020].

[31] Carlotti APDCP, Carvalho WBD, Johnston C, Rodriguez IS, Delgado AF. COVID-19 Diagnostic and management protocol for pediatric patients. Clinics 2020; 75:e1894. https://doi.org/10.6061/clinics/2020/e1894

[32] Behzadi MA, Leyva-Grado VH. Overview of current therapeutics and novel candidates against influenza, respiratory syncytial virus and Middle East respiratory syndrome coronavirus infections. Front Microbiol 2019; $10: 1327$. https://doi.org/10.3389/fmicb.2019.01327

[33] Centers for Disease Control and Prevention. If You Are Immunocompromised, Protect Yourself From COVID-19. Available from: https://www.cdc.gov/coronavirus/2019-ncov/need-extra-precautions/immunocompromised.html. [Accessed on May 18, 2020].

[34] Meng L, Hua F, Bian Z. Coronavirus disease 2019 (COVID-19): emerging and future challenges for dental and oral medicine. J Dent Res 2020; 99(5):481-7. https://doi.org/10.1177/0022034520914246

[35] Amber A, Patel B, Ruparel NB, Diogenes A, Hargreaves KM. Coronavirus Disease 19 (COVID-19): implications for Clinical Dental Care. J Endod 2020; 46(5):584-95. https://doi.org/10.1016/j.joen.2020.03.008

[36] Franco JB, Camargo AL, Peres MPSM. Cuidados odontológicos na era do COVID-19: recomendações para procedimentos odontológicos e profissionais. Rev Assoc Paul Cir Dent 2020; 74(1):18-21. [In Portuguese]. 
[37] Ambigapathy S, Rajahram GS, Shamsudin UK, Khoo EM, Cheah WK, Peariasamy KM, et al. How should front-line general practitioners use personal protective equipment (PPE)? Malays Fam Physician 2020; 15(1)2-5.

[38] Scottish Dental Clinical Effectiveness Programme. Drugs for the Management of Dental Problems During COVID-

19 Pandemic. Available from: http://www.sdcep.org.uk/published-guidance/acute-dental-problems-covid-19/. [Accessed on May 11, 2020]. 